\title{
DOCUMENTO
}

\section{Vacuna anti neumocóccica conjugada heptavalente}

\author{
DECLARACION DEL COMITE CONSULTIVO DE INMUNIZACIONES
}

\author{
HEPTAVALENT PNEUMOCOCCAL CONJUGATE VACCINE \\ STATEMENT OF THE ADVISORY COMMITTEE FOR IMMUNIZATION
}

Disponer de medidas de prevención específicas y eficaces contra Streptococcus pneumoniae es uno de los grandes anhelos de la Salud Pública mundial, dado que esta bacteria es el primer agente causal de enfermedades invasoras en la infancia, tales como bacteremias ocultas, meningitis, septicemia, peritonitis primaria, bacteremias fulminantes y otras, a la vez que constituye la principal etiología de infecciones canaliculares como otitis media aguda (OMA) o sinusitis aguda y neumonías, con especial mayor frecuencia en lactantes.

En Chile se ha registrado recientemente una vacuna conjugada contra $S$. pneumoniae, la primera autorizada por la Food and Drugs Administration (F.D.A.) de E.U.A. y cuyos resultados de eficacia han sido difundidos ampliamente.

La introducción al mercado chileno y latinoamericano de la vacuna anti neumocóccica hepta (7) - valente, PREVENAR $®$, fabricada por Wyeth Lederle, ha suscitado un interés especial y expectación en la comunidad médica latinoamericana exigiendo de los especialistas una orientación técnica sobre sus bondades, indicaciones y trascendencia para la prevención de las enfermedades causadas por S. pneumoniae en nuestra realidad epidemiológica.

El Comité Consultivo de Inmunizaciones (CCI) de la Sociedad Chilena de Infectología ha efectuado una exhaustiva revisión de los antecedentes técnicos de esta vacuna conjugada heptavalente generados en EUA, Europa e
Israel. Así mismo, se recolectaron y analizaron los antecedentes nacionales disponibles a la fecha sobre la epidemiología de las enfermedades neumocóccicas en la población infantil bajo 5 años de edad, los que se ha tomado en consideración para elaborar esta declaración.

\section{ANTECEDENTES DE LA VACUNA}

Composición. Se trata de una vacuna heptavalente conjugada con proteína de la toxina diftérica mutante CRM 197 (atóxica), antes utilizada en la elaboración de una de las vacunas anti Haemophilus influenzae b, licenciada y empleada en Chile (HibTiter®).

La vacuna Prevenar ${ }^{\circledR}$ contiene como antígeno inmunizante $2,0 \mu \mathrm{g}$ de los siguientes polisacáridos (serotipos): 4 - 9V - 14 - 19F - 23F, $2 \mu \mathrm{g}$ del oligosacárido del serotipo18C, y $4 \mu \mathrm{g}$ del polisacárido $6 \mathrm{~B}$. Su formulación es líquida y la presentación individual está contenida en $0,5 \mathrm{ml}$.

Los serotipos mencionados fueron seleccionados por representar aproximadamente el $80 \%$ de los serotipos aislados en procesos invasores observados en E.U.A. en un período superior a 15 años, sobre $66 \%$ de los recuperados en otitis media aguda, a la vez que representan cerca de $80 \%$ de los serotipos con resistencia a antimicrobianos en esa realidad epidemiológica.

Inmunogenicidad. Los principales estudios de inmunogenicidad, seguridad y eficacia clínica fueron efectuados en California, E.U.A., 
por la institución Kaiser Permanente Vaccine Study Center (H R Shinefield et al 2000).

La respuesta inmune de lactantes a los 7 serotipos fue satisfactoria en 2 ensayos, alcanzando después de 3 dosis (2 - 4 - 6-meses), concentraciones séricas de anticuerpos anti PS superiores a 0,1 $\mu \mathrm{g} / \mathrm{ml}$. (M B Rennels 1998, H Shinefield, 1999). Una cuarta dosis administrada con posterioridad a los 12 meses de edad estimuló una respuesta constante y de una magnitud significativa (título pre refuerzo en el rango $0,3-1,4 \mu \mathrm{g} / \mathrm{ml}$, título post refuerzo en el rango $2,5-8,2 \mu \mathrm{g} / \mathrm{ml})$.

Eficacia y efectividad. En un estudio de campo efectuado durante 4 años (1995-1999) en niños bajo 4 años de edad - la vacuna fue administrada en 4 dosis, a los 2 - 4 - 6 y 12 a 15 meses de edad (n: 18.927), empleando como grupo control la vacuna anti meningocóccica $\mathrm{C}$ conjugada con el mismo carrier, CRM197, (n: 18.941) - se comprobó una eficacia protectora contra enfermedad invasora causada por los serotipos incluidos en la vacuna, de $97,4 \%$ (IC95\%, 82,7-99,9\%) y una efectividad de 93,9\%. Al momento del análisis interino del estudio, la mayoría de los casos presentados durante la intensa y exigente vigilancia epidemiológica, pertenecían al grupo control y correspondieron a bacteremias (13/17). Los serotipos vaccinales aislados en ellos correspondieron al 6B, 9V, 14, 18C, 19F y 23F.

La eficacia en la prevención de neumonía, identificada por la presencia de una imagen radiológica, fue de $33 \%$ y de $73 \%$ si esa imagen era de más de $2,5 \mathrm{~cm}$ de diámetro.

En otro estudio diseñado para evaluar su protección contra OMA, en un total de 1.662 lactantes fineses vacunados a los 2 - 4 - 6 y 12 meses de edad, su eficacia fue de $34 \%$ contra los episodios de OMA causados por $S$. pneumoniae $(57 \%$ si se consideran sólo las OMA causadas por los serotipos vaccinales) (T Kilpi et al, 2000).

Seguridad. Los resultados de ambos estudios demostraron además que la vacuna es altamente segura, no produciendo reacciones adversas más frecuentes ni severas que la vacuna DTP administrada en las mismas edades.

Efectos sobre el estado de portación. Empleando una vacuna conjugada con toxina diftérica CRM 197 pero nonavalente, que incorporó además los serotipos 1 y 5, pudo comprobarse la significativa reducción en la portación faríngea de los 9 serotipos vaccinales, estable en el tiempo, en comparación con un grupo control (de 42 a $17 \%$ versus de 39 a $27 \%$ ), en niños de 12 a 35 meses de edad. Estos serotipos fueron reemplazados por serotipos no vaccinales (R Dagan 1998), para los que se ha descrito un menor grado de resistencia antimicrobiana $y$, hasta hoy en día, son considerados menos patógenos que los vaccinales.

\section{ANTECEDENTES EPIDEMIOLÓGICOS NACIONALES}

Estudio SIREVA. Por iniciativa de SIREVA (Sistema Regional de Vacunas) y OPS se efectuó entre los años 1993 y 1996, una recolección y serotipificación de cepas de $S$. pneumoniae aislados de procesos invasores (sangre, LCR, otros sitios estériles) en los siguientes 6 países de Latinoamérica: México, Colombia, Brasil, Uruguay, Argentina y Chile. Su objetivo fue documentar para la región la importancia relativa de los serotipos de $S$. pneumoniae provenientes de afecciones invasoras en niños bajo 5 años de edad. En este protocolo se demostró que en 198 cepas provenientes de Chile (Región Metropolitana R.M. y VII Región) los serotipos predominantes fueron los siguientes: 14 - 5 y 1 , con una importancia relativa de $15,7 \%$ para los dos primeros y de $13,6 \%$ para el último (D A Kertesz et al, 1998).

Vigilancia del Laboratorio Nacional de Referencia, Instituto de Salud Pública. Mediante una vigilancia epidemiológica activa liderada por el CVD-Chile, de un total de 609 cepas obtenidas en niños bajo 5 años de edad con cuadros invasores (entre los años 1994 y 2000), y enviadas a serotipificar desde centros hospitalarios de la R.M., los serotipos más prevalentes fueron los siguientes: 1 - 5 y 14, sumando en conjunto un 43\%. (R Lagos, comunicación personal). Aproximadamente $70 \%$ de las cepas referidas al ISP provenían de la R.M. y tan sólo $30 \%$, del resto de los Servicios de Salud del país (Fuente: Diagnóstico de Situación Instituto de Salud Pública, año 2000). Los 
antecedentes epidemiológicos regionales disponibles apuntan hacia la uniformidad de serotipos a lo largo del país.

\section{CONCLUSIONES}

- De ambos estudios se desprende que los serotipos 1 y 5 son responsables de $\sim 30 \%$ de los episodios de infección invasora detectados en niños bajo 5 años de edad. La alta prevalencia de estos dos serotipos, prácticamente ausentes en países industrializados, es un atributo característico de la epidemiología de las infecciones invasoras causadas por S. pneumoniae en países en desarrollo, como fue documentado para toda Latinoamérica en el estudio de SIREVA.

- Según esta información epidemiológica, la vacuna heptavalente Prevenar® tendría una cobertura teórica contra un $45 \%$ de los serotipos causantes de enfermedad invasora en niños bajo 5 años de edad en nuestro medio. Si se cumpliese la hipótesis de que existe cobertura cruzada entre los serotipos de un mismo serogrupo (por ejemplo 6B/
6A), la cobertura teórica alcanzaría a 57\%.

- En suma podemos concluir que se dispone de una nueva vacuna anti neumocóccica, la primera apropiada para utilizar en lactantes, altamente segura, de efectividad probablemente menor en nuestro medio a la observada en E.U.A. donde fuera desarrollada. Se reconoce en esta vacuna un progreso importante en la investigación de una vacuna óptima contra las enfermedades causadas por $S$. pneumoniae en niños, no constituyendo el término de esta búsqueda.

- Igualmente, y de acuerdo a la situación epidemiológica chilena descrita, no se estima éste un recurso a considerar en programas nacionales de inmunización para niños sanos. Sin embargo, y en una perspectiva individual, ética y de beneficencia, aunque hoy en día esta vacuna no está al alcance de todo el público por razones de costo, la comunidad médica debe estar interiorizada de las bondades y limitaciones de esta nueva vacuna, y la población en general, debe ser oportunamente informada de la existencia en el mercado nacional de esta herramienta de prevención. 